\title{
Postural control in children receiving intervention using the Astronaut Training Protocol
}

*Gabrielle Katzenellenbogen, BSc OT (Wits); MSc OT (Wits). https://orcid.org/0000-000 I-738 I-6332

Occupational Therapist - private practice, Postgraduate student, Dept of Occupational Therapy, School of Therapeutic Sciences, Faculty of Health Sciences, University of Witwatersrand, Johannesburg, South Africa

\section{Denise Franzsen, BSc OT (Wits); MSc OT (Wits); DHT (UP); PhD (Wits). https://orcid.org/0000-000 I-8295-6329}

Sessional lecturer, Dept of Occupational Therapy, School of Therapeutic Sciences, Faculty of Health Sciences, University of Witwatersrand, Johannesburg, South Africa

Janine van der Linde, BSc OT (UFS); MSc OT (Wits); PhD (Wits). https://orcid.org/0000-0003-1067-9494 Lecturer, Department of Occupational Therapy, School of Therapeutic Sciences, Faculty of Health Sciences, University of Witwatersrand, Johannesburg, South Africa

Introduction: The vestibular system plays an important role in postural control and an upright posture when seated at a table. Some children have difficulty with their in-seat posture resulting in increased in-seat movement. This research investigated the effect of the Astronaut Training Protocol on a child's vestibular processing and postural control, and by extension their in-seat behaviour.

Method: A case study research design with multiple data sources was used with four participants identified presenting with dysfunction in in-seat posture and in-seat movement. Data were collected over three phases: Pre-Astronaut Training (Baseline), Post-Astronaut Training (Intervention) and Withdrawal. The Pre-Astronaut Training and Withdrawal phases consisted of four sessions of sensory-based occupational therapy while the intervention phase included eight Astronaut Training sessions in addition to regular sensory-based occupational therapy. Four assessments were used to determine vestibular and postural control changes at each phase: Movement ABC one-leg balance, Post-rotary Nystagmus (PRN) test, in-seat posture assessment (designed for the purpose of this study), and in-seat movement through the collection of data using an accelerometer.

Results: Participants' scores differed, depending on their initial ability to tolerate rotary input. This research showed that change in vestibular function and postural control differed for participants who could tolerate rotary input and those who were over-reactive to rotary input at the start of the study. Generally, the participants who were over-reactive to rotary input showed greater improvement Post-Astronaut Training with continued smaller improvements into the Withdrawal phase. Participants who could tolerate rotary input showed improvement in in-seat posture and in-seat movement during the Post-Astronaut training phase and deteriorated during the Withdrawal phase.

Conclusion: The Astronaut Training Protocol can improve vestibular function and postural control in children with poor in-seat posture and in-seat movement, although the frequency and intensity of the programme still need to be confirmed.

Keywords: vestibular processing, in-seat movement, in-seat posture, reaction to vestibular input, sensory-based occupational therapy, Astronaut Training Protocol.

\section{INTRODUCTION}

The vestibular system is responsible for maintaining the head in midline, upright body posture, postural control, balance, and providing a stable visual field'. To succeed in the classroom, children need to maintain an adequate upright posture in sitting at a desk while performing academic tasks. Low postural tone and a lack of adequate postural control may result in an inability to maintain this posture. Children with these deficits tend to flex over the desk and use their non-dominant hand to prop up their head while working on school-related tasks ${ }^{2,3}$. They may seek additional sensory input (such as proprioceptive and vestibular input) by moving in their seats ${ }^{4}$. This movement facilitates their postural control but compromises their ability to pay attention in class. The conscious effort required to monitor and maintain their posture as well as the fatigue experienced, further compromises the mental energy needed for learning ${ }^{2,5}$. Therefore, children with poor vestibular processing may display decreased balance, poor posture, a lack of attention and tend to move or fidget constantly in their seats ${ }^{4}$.

\section{LITERATURE REVIEW}

Postural control is the ability to sustain alignment of the body whilst upright in space. It requires the development of muscle strength for anti-gravity movements, proximal axial control, dynamic cocontraction and mature postural reactions ${ }^{6}$. To achieve postural control and upright posture, the integration of the vestibular, somatosensory, visual ${ }^{6}$ and musculoskeletal ${ }^{7}$ systems, is needed ${ }^{7}$. The vestibular system is situated in the inner ear and consists of the semicircular canals and the otolith organ. It supports several important functions related to postural control, mobility, balance reactions, the upright positioning of the head in relation to gravity, maintaining 
a stable visual field, eye movements, postural adjustments, bilateral coordination and autonomic nervous system functions ${ }^{8-10}$.

Vestibular impulses need to be integrated with the vestibularspinal tracts and reticular-spinal tracts. These tracts play a role in postural adjustments in the trunk and upper limbs, and to a smaller extent on the lower limbs which have an impact on one leg balance. Children with vestibular difficulties may have an over-reaction to equilibrium demands and try to over-compensate. The lack of integration between the vestibular and proprioceptive systems can cause poor equilibrium, righting reactions and thus poor postural control" '. These functions are required to successfully perform activities of daily living ${ }^{\prime 2}$. Children require an intact vestibular system to develop sufficient gross motor and fine motor skills which facilitate their appropriate interaction and participation in the classroom ${ }^{8-10}$.

In modern times, children participate in fewer activities which facilitate gross motor skills and postural control due to the increase in the development of technology and time spent on screens ${ }^{13}$ as well as the increase in time spent sitting during structured activities in the classroom ${ }^{3}$. Preschool and Grade R learners spend less time on free play and exploration since there is more emphasis on academically orientated activities and table-top tasks. According to Bassok, et al. ${ }^{14}$ there is more pressure on teachers to get children academically ready for Grade I. A deterioration in children's posture and the increased need to fidget have therefore been observed, particularly in children diagnosed with developmental disabilities such as attention deficit hyperactivity disorder. $\mathrm{Hanscom}^{3}$ explains that this is due to the decreased time children spend moving and engaged in physical play, resulting in them not developing sufficient core muscle strength to keep themselves sitting upright in the classroom. Teachers have also reported that more students are struggling to sit and pay attention and are constantly fidgeting or getting out of their chairs ${ }^{3}$.

To succeed in a classroom, a child needs to be able to maintain an upright posture. Fidgeting is a compensatory strategy for children in an attempt to gain more sensory input to feel alert enough to focus, however, often this movement does not provide enough intensity to sustain the focus required ${ }^{3}$. This negatively impacts on the development of fine motor skills such as handwriting as there may not be sufficient proximal stability in the shoulder and forearm to allow for hand dexterity, pencil control and fine motor skills ${ }^{15-17}$. Occupational therapists are involved in the assessment and treatment of postural control but there is a limited number of standardised assessments available for evaluating vestibular function in children. The Post-rotary Nystagmus (PRN) Test, a subtest of the Sensory Integration and Praxis Test (SIPT), assesses the integrity of the vestibular-ocular reflex ${ }^{18}$ and the balance subtests from The Movement $A B C 2{ }^{19}$ and SIPT, provide information about vestibular processing although it must be recognised that they were not designed to assess vestibular function ${ }^{12}$.

Postural changes over time and movement while sitting may be considered for the assessment of in-seat posture. Many studies focused on the seated posture by looking at the centre of pressure using a force platform ${ }^{20,21}$. This method is not however, always viable in a therapy setting. Other methods such as video recordings ${ }^{22}$ or observational scales ${ }^{23}$ have been used to assess postural control and are easier to implement in private practice. There is a need for more research into alternative ways to measure seated postural control (for example, a descriptive assessment to measure posture in children without severe motor impairments).

Intervention for postural control in occupational therapy differs, and one programme that can be considered is the Astronaut Train- ing Protocol, which was designed, based on the sensory integration framework, to stimulate and integrate the vestibular, visual, and auditory systems and expand on treatment strategies and clinical reasoning ${ }^{24}$. The protocol allows for stimulation of the vestibular system through rotation, inversion and linear movement.

Rotation is used to activate the semi-circular canals of the vestibular system by the therapist rotating the child once every two seconds in time with the Astronaut Training music. This is done in sitting and side-lying on the left and right sides. Through rotation, the ocular muscles are activated due to the post-rotary nystagmus. The visual system is stimulated by using smooth pursuit and saccadic eye movements horizontally, vertically, and diagonally, as well as convergence and divergence. This is done by following moving penlights held by the therapist. Throughout the programme, specific music tracks are played to stimulate the auditory system to encourage spatial awareness and timing of movement. Vestibular and core activation activities are used at the end of each Astronaut Training session to further activate and regulate the vestibular system ${ }^{24}$. Activities done in prone and supine (such as swinging in a hammock swing or using a scooter board) can further activate postural control.

The Astronaut Training Protocol may be beneficial in the direct treatment of the vestibular system due to the direct stimulation of the semi-circular canals and otolith organs. In terms of treating postural control, it can be hypothesised that using the core activities after vestibular stimulation, anti-gravity movements can be stimulated to strengthen the trunk and neck extensors and flexors required to keep an upright posture. These activities require the appropriate feedback and anticipatory response for the child to adjust their body to master the activity, have a theme and music (which children find enjoyable) and therefore assist in motivation and volition which are important components in the motor learning theory ${ }^{6}$. The Astronaut Training Protocol is used as an adjunct to sensory-based occupational therapy ${ }^{25}$ since literature indicates that the vestibular system is the foundation for the postural control needed to maintain and upright posture at the table.

Even though this programme is well-known in many countries, and in addition, is used by $40 \%$ of occupational therapists with an interest in sensory integration in the United States of America ${ }^{24}$, there is no published research on the effectiveness of the programme. Sixty three percent of these therapists use it to stimulate postural-ocular control, $57.9 \%$ for oculomotor control and $46.4 \%$ for balance skills. On average, this programme is used for up to three months as a sensory-based intervention. No research could be found on the recommended frequency and intensity when using the protocol. There is therefore a need for evidence-based research to assist in the therapist's clinical decision-making when selecting the Astronaut Training Protocol as an intervention strategy.

The aim of this study was to determine the change in balance and postural control when children receive intervention using the Astronaut Training Protocol and whether an impact on their in-seat posture and in-seat movement was observed. In addition, it looked at whether there was carry over after withdrawal of the Astronaut Training Protocol.

\section{METHODOLOGY Study Design}

A descriptive case study ${ }^{26}$ with multiple data sources was conducted on four participants, between the ages of five years three months and six years four months. 


\section{Population and sampling}

Participants were recruited from a private paediatrics practice in Johannesburg, South Africa, via convenient sampling. Participants who displayed poor in-seat posture, in-seat movement (i.e., fidgeting) and vestibular difficulties were identified via parent observations and occupational therapy assessment of the children's ability to assume and maintain the supine flexion and prone extension positions based on the clinical observations assessment ${ }^{27}$. The ability to assume these positions is a strong indicator of intact vestibular and proprioceptive systems $\mathrm{s}^{25}$. All participants were already receiving input from the same occupational therapist who documented their responsiveness to rotary input and who implemented the Astronaut Training Protocol. The assessments were conducted by an independent occupational therapist to prevent bias.

\section{*Ethics}

Signed, informed consent was obtained from parents and informed assent was obtained from the participants for participation in the study and for the children to be videoed. Ethical clearance was obtained from the ethics committee at the University of Witwatersrand (MI70522). Parents and children were assured that the participation was voluntary, and they could withdraw at any time with no negative consequences. Parents completed a background questionnaire, and it was documented whether the participant was on medication for concentration.

\section{Data Collection}

Data were collected on each participant on three occasions:

- Pre-Astronaut Training to provide baseline data,

- Post-Astronaut Training (after eight Astronaut Training sessions with sensory-based occupational therapy),

- Withdrawal (four sensory-based occupational therapy sessions' later) without implementation of the Astronaut Training Protocol.

\section{Research Instruments}

The following assessments were used to measure change in vestibular processing and postural control:

\section{One-Leg Balance}

The one-leg balance was assessed using the Balance subtest of the Movement ABC-2. Participants were asked to balance on one leg with their eyes open. Raw scores were converted into standardised score ${ }^{19}$ and then $\mathrm{z}$ scores. $Z$ scores between $-I$ and $+I$ are within the typical range. Static balance includes vestibular, proprioception and visual processing, particularly the macular receptors in the otolith organs of the vestibular system ${ }^{18}$. The test-retest reliability of the balance subtest was 0.7319 .

\section{Post-rotary Nystagmus (PRN)}

The Post-rotary Nystagmus (PRN) subtest from the Sensory Integration and Praxis Test (SIPT) was used to assess the integrity of the vestibular-ocular reflex, provided there are no peripheral vestibular problems ${ }^{18}$. Scores were converted to $\mathrm{z}$ scores using the Sensory Integration and Praxis Test computerised scoring software. Scores between $-I$ and $+I$ are within the typical range. A low PRN score indicates low central nervous system responsivity to vestibular input, whilst a high score indicates poor inhibition of the central nervous system on the reflex ${ }^{18}$. Neither of these are favourable.
This assessment was completed after the balance assessment as some children may get disorganised by the rotary input. The assessment has good interrater reliability of $0.98^{18,28}$ and test-retest reliability of $0.83^{29}$ and $0.80^{30}$. Participants' responses to the rotary input were monitored to determine if any participants had difficulty modulating this input. Signs of difficulties in sensory modulation i.e., sensory over-reactivity such as flushing, headaches, nausea, sweating or dilation of pupils were recorded. These observations were extremely important to determine how much rotary input the participant could tolerate, which impacted the amount of rotation they then received during the Astronaut Training Protocol.

\section{In-seat posture}

To analyse in-seat posture, a posture assessment was developed based on the Chailey Levels of Postural Ability ${ }^{31}$. This assessment was adapted as it was designed to assess children with neurological impairment. The participants' in-seat behaviour was assessed by determining in-seat posture during a 10 -minute table-top task they were asked to complete while seated. The participants were assessed and re-assessed in the same occupational therapy room, with the same activity, table and chair, at a similar time of day. A video camera was placed on the participants' non-dominant side to obtain a full lateral view. Their posture was analysed on a frame from the video recording at two separate points: at 7.30 minutes in (posture I) and then again at 9.30 minutes in (posture 2). These two screenshots at the specific time were used to prevent examiner bias when assessing their posture.

The posture was analysed according to descriptors of deviation from the upright neutral posture for the knees and feet positioning, buttocks in contact with the chair, pelvic girdle positioning, hip position, trunk position, shoulders, head alignment and engagement of arms in the activity. A score of one was given for each descriptor which indicated deviation from the neutral upright position in sitting. Scores closer to zero indicated optimal posture. Since the results for the two posture assessments were similar, they were combined and averaged for in-seat posture. Although this assessment does not have proven validity, the use of video assessment meant that the results could be reassessed and checked for accuracy.

\section{In-seat movement}

The ActiGraph accelerometer (ActiGraph GT3X+, ActiGraph, Pensacola, FL) was used to measure motor activity through detection of the intensity of movement. It measured sedentary activity by using low movement counts ${ }^{32,33}$. The accelerometer was worn on an elastic band around the participant's waist over their clothing to assess movement of the trunk while the participant was seated. ActiGraphs have a reliability of 0.90 to 0.99 if placed on the same individual in the same place ${ }^{34}$. The accelerometer was initialised to record at a sample rate of $100 \mathrm{~Hz}$ in 10 second segments. The participant's in-seat movement was isolated and tracked assessing three axes, thus measuring vertical, horizontal and perpendicular movement ${ }^{33}$. These scores were combined to provide a total score movement called vector magnitude.

\section{Intervention}

All participants received 12 occupational therapy sessions in total: eight Astronaut Training sessions (intervention) in conjunction with sensory-integration based occupational therapy, and four sensorybased occupational therapy sessions without the Astronaut Training 


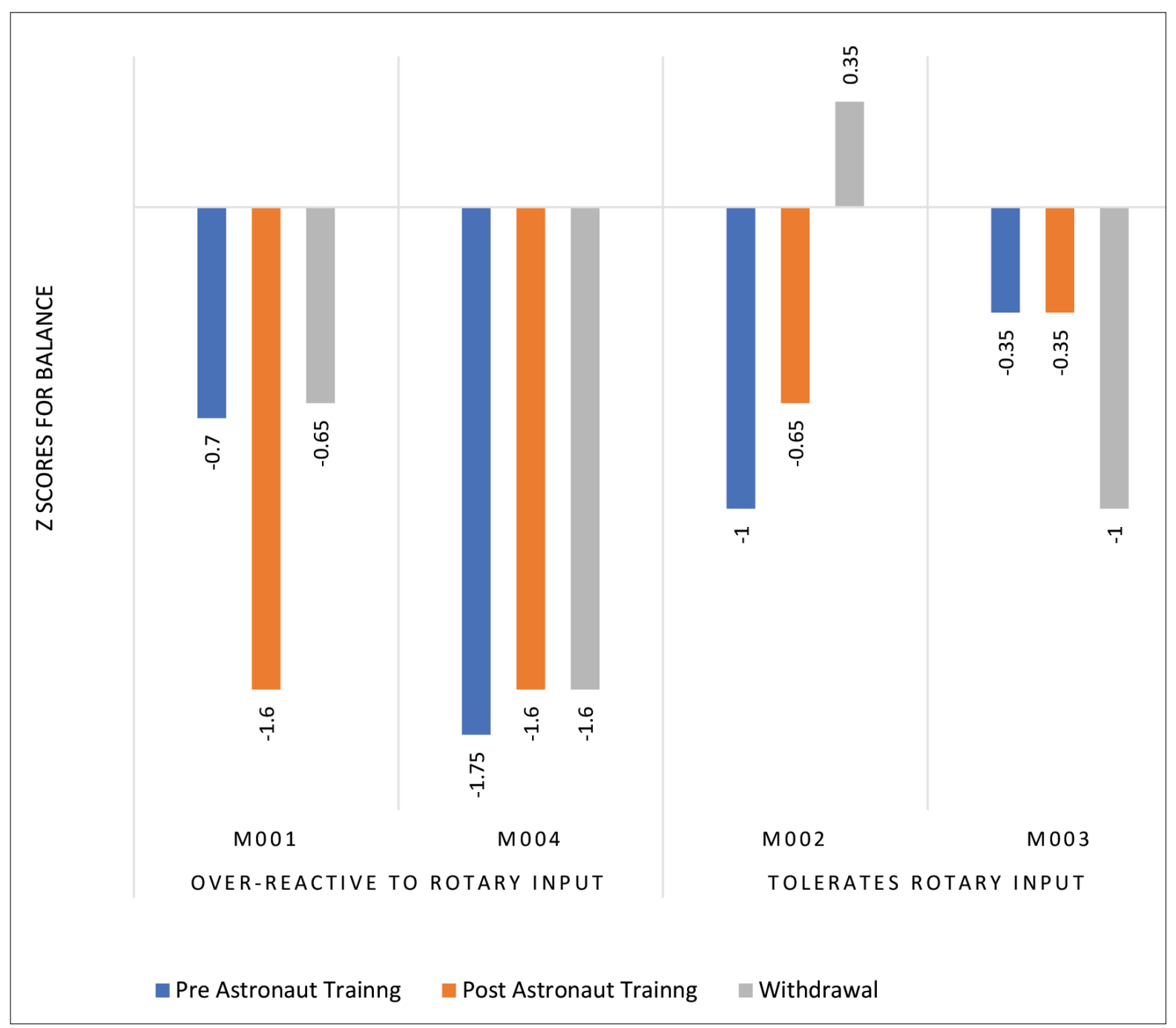

Figure I: Balance scores for each participant $(n=4)$

Table I: Frequency of intervention

\begin{tabular}{|l|l|l|l|}
\hline & Participant & $\begin{array}{l}\text { Number of } \\
\text { weeks Astro- } \\
\text { naut Training } \\
\text { took place }\end{array}$ & $\begin{array}{l}\text { Number } \\
\text { of weeks } \\
\text { Withdrawal } \\
\text { took place }\end{array}$ \\
\hline \multirow{2}{*}{$\begin{array}{l}\text { Over- } \\
\text { reactive to } \\
\text { rotary input }\end{array}$} & M00I & 3 weeks & 4 weeks \\
\cline { 2 - 4 } & M004 & 3 weeks & 5 weeks \\
\hline $\begin{array}{l}\text { Tolerates } \\
\text { rotary input }\end{array}$ & M002 & 6 weeks & 4 weeks \\
\cline { 2 - 4 } & M003 & 7 weeks & 10 weeks \\
\hline
\end{tabular}

(Withdrawal). Sensory-based occupational therapy was conducted by the same occupational therapist who also implemented the Astronaut Training Protocol. This therapist was qualified in Ayres Sensory Integration ${ }^{\circledR}$ as well as other sensory integration-based interventions such as the Astronaut Training Protocol. All participants received eight sessions for the Astronaut Training Protocol but the frequency depended on participants' schedules.

Therapy attendance varied per participant, some attending sensory-based occupational therapy once per week with participants who were over-reactive to rotary input attending therapy more often (Table I above). Therapy attendance depended on participants' and parents' schedules as well as school holidays. One participant, M003, was inconsistent with her therapy attendance during the Withdrawal phase and this phase took place ten weeks later as opposed to four weeks.

\section{Data Analysis}

Data were analysed through descriptive statistics. Demographics of age, gender and taking medication for concentration were analysed as nominal data, whilst tolerance for rotary input was analysed as interval data. Pre-test and post-test assessments were ordinal and interval but were analysed descriptively due to the small number of participants ${ }^{35}$.

\section{RESULTS}

Participants ranged from five years three months to six years four months, three of which were male and one of which was female. All participants were white, attended various private schools in Johannesburg, as well as occupational therapy sessions with the same therapist at the private practice where the study was conducted. None of the participants were on medication for their concentration during the study except participant $\mathrm{M} 003$ who started medication during the Withdrawal phase. Two participants (M00I and M004) were overreactive to rotary vestibular input and their tolerance for the amount of rotation was carefully graded. When sympathetic nervous system signs of overstimulation such as flushing, going pale, increased breathing or heart rate, sweaty hands or feeling nauseous were observed, they were counteracted with proprioceptive activities or applying ice to the palms of the hands, temples of the head and behind the neck ${ }^{24}$.

\section{Vestibular function}

Changes in vestibular function were analysed at Pre-Astronaut 


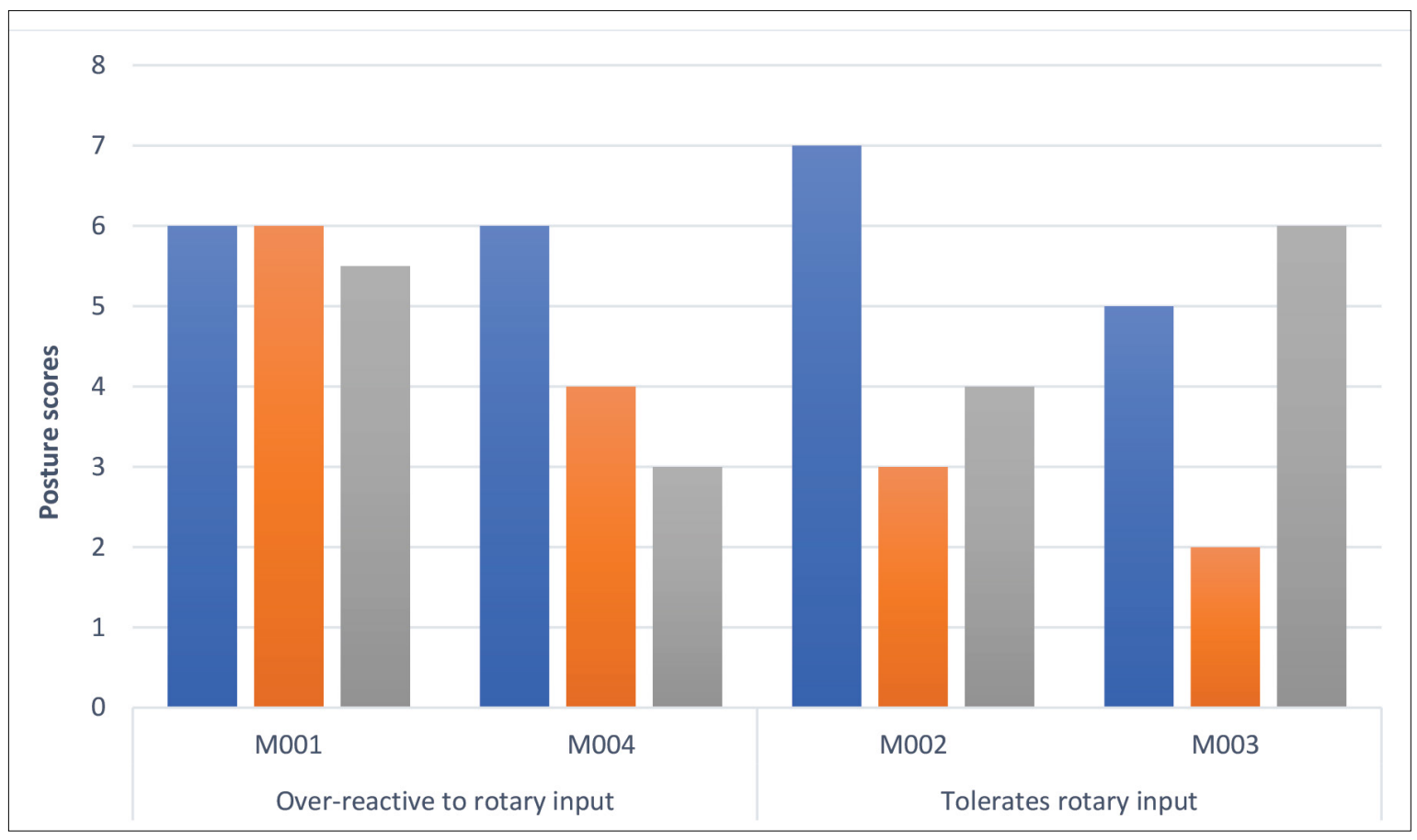

Figure 2:

In-seat posture scores for each participant $(n=4)$.

Table II: Combined Balance z scores at Pre-Astronaut Training, Post-Astronaut Training and Withdrawal phases

\begin{tabular}{|c|c|c|c|}
\hline Balance & $\begin{array}{l}\text { Median } \\
\text { (Lower } \\
\text { Quartile } \\
\text { and Upper } \\
\text { Quartile) }\end{array}$ & \multicolumn{2}{|c|}{ Difference in Median Scores } \\
\hline \multicolumn{4}{|c|}{ Over-reactive to rotary input $(n=2)$} \\
\hline $\begin{array}{l}\text { Pre-Astronaut } \\
\text { Training }\end{array}$ & $\begin{array}{l}-1.22(-1.73 \\
-0.70)\end{array}$ & \multirow{2}{*}{$\begin{array}{l}\text { Pre-Astronaut } \\
\text { Training to } \\
\text { Post-Astronaut } \\
\text { Training }\end{array}$} & \multirow{2}{*}{-0.38} \\
\hline \multirow[t]{2}{*}{$\begin{array}{l}\text { Post- Astro- } \\
\text { naut Training }\end{array}$} & \multirow[t]{2}{*}{$\begin{array}{l}-1.60(-1.60 \\
-1.60)\end{array}$} & & \\
\hline & & \multirow{2}{*}{$\begin{array}{l}\text { Post-Astronaut } \\
\text { Training to } \\
\text { Withdrawal }\end{array}$} & \multirow[b]{2}{*}{0.48} \\
\hline Withdrawal & $\begin{array}{l}-1.12(-1.60 \\
-0.65)\end{array}$ & & \\
\hline \multicolumn{4}{|c|}{ Tolerates rotary input $(n=2)$} \\
\hline $\begin{array}{l}\text { Pre-Astronaut } \\
\text { Training }\end{array}$ & $\begin{array}{l}-0.67(-1.00 \\
-0.70)\end{array}$ & \multirow{2}{*}{$\begin{array}{l}\text { Pre-Astronaut } \\
\text { Training to } \\
\text { Post-Astronaut } \\
\text { Training }\end{array}$} & \multirow{2}{*}{0.17} \\
\hline \multirow{2}{*}{$\begin{array}{l}\text { Post- Astro- } \\
\text { naut Training }\end{array}$} & \multirow{2}{*}{$\begin{array}{l}-0.50(-0.65 \\
-0.35)\end{array}$} & & \\
\hline & & \multirow{2}{*}{$\begin{array}{l}\text { Post-Astronaut } \\
\text { Training to }\end{array}$} & \multirow[b]{2}{*}{0.18} \\
\hline Withdrawal & $\begin{array}{l}-0.32 \\
(-1.00 ;-0.35)\end{array}$ & & \\
\hline
\end{tabular}

Training, Post-Astronaut Training and after Withdrawal by assessing post-rotary nystagmus and balance:

\section{Post-rotatory Nystagmus (PRN)}

Post-rotary Nystagmus scores were within the typical range for all participants throughout the study. Scores are therefore not included in the analysis of the intervention. It is likely that these scores were typical as participants were already undergoing sensory-based occupational therapy and thus received stimulation to their semi-circular canals. The observations made regarding tolerance of rotary input were extremely important in the implementation of the protocol.

Table III: Combined in-seat posture scores at Pre-Astronaut Training, Post-Astronaut Training and Withdrawal phases

\begin{tabular}{|c|c|c|c|}
\hline $\begin{array}{l}\text { In-seat } \\
\text { posture }\end{array}$ & $\begin{array}{l}\text { Median } \\
\text { (Lower Quatile } \\
\text { and Upper } \\
\text { Quartile) }\end{array}$ & \multicolumn{2}{|l|}{$\begin{array}{l}\text { Difference in Median } \\
\text { Scores }\end{array}$} \\
\hline \multicolumn{4}{|c|}{ Over reactive to rotary input $(n=2)$} \\
\hline $\begin{array}{l}\text { Pre-Astro- } \\
\text { naut Training }\end{array}$ & $7(6.00-6.00)$ & \multirow{2}{*}{$\begin{array}{l}\text { Pre-astronaut Training } \\
\text { to Post-Astronaut } \\
\text { Training }\end{array}$} & \multirow[t]{2}{*}{3} \\
\hline Post- Astro- & $4.25(4.00-6.00)$ & & \\
\hline Withdrawal & $4(3.00-5.50)$ & $\begin{array}{l}\text { Post-Astronaut Training } \\
\text { to Withdrawal }\end{array}$ & 0.25 \\
\hline \multicolumn{4}{|c|}{ Tolerates rotary input $(n=2)$} \\
\hline $\begin{array}{l}\text { Pre-Astro- } \\
\text { naut Training }\end{array}$ & $6(5.00-7.00)$ & \multirow{2}{*}{$\begin{array}{l}\text { Pre-Astronaut Training } \\
\text { to Post-Astronaut } \\
\text { Training }\end{array}$} & \multirow[t]{2}{*}{3.5} \\
\hline $\begin{array}{l}\text { Post- Astro- } \\
\text { naut Training }\end{array}$ & $2.5(1.00-3.00)$ & & \\
\hline Withdrawal & $5(4.00-6.00)$ & $\begin{array}{l}\text { Post-Astronaut Training } \\
\text { to Withdrawal }\end{array}$ & -2.5 \\
\hline
\end{tabular}

\section{Balance}

Participants M00 I and M004 who were over-reactive to rotary input had $\mathrm{z}$ scores greater than - I.5, indicting dysfunction Post-Astronaut Training with participant $\mathrm{MOOI}$ showing deterioration in his score. The participants who tolerated rotary input all had $\mathrm{z}$ scores of less than -I Post-Astronaut Training and their scores improved or remained the same compared to Pre-Astronaut Training. At Withdrawal participant $\mathrm{MOOI}$ showed improvement with the score being better than that at Pre-Astronaut Training. Participant M004 showed no further improvement on Withdrawal. Participant M002 was the only participant to show improvement in balance over the three phases, whereas participant M003's balance score was lower at Withdrawal which could have been due to inconsistent therapy attendance in this phase (Figure I p68)

Table II (adjacent) indicates that for balance, the scores decreased from Pre-Astronaut Training to Post-Astronaut Training for participants who are over-reactive to rotary input, but an im- 


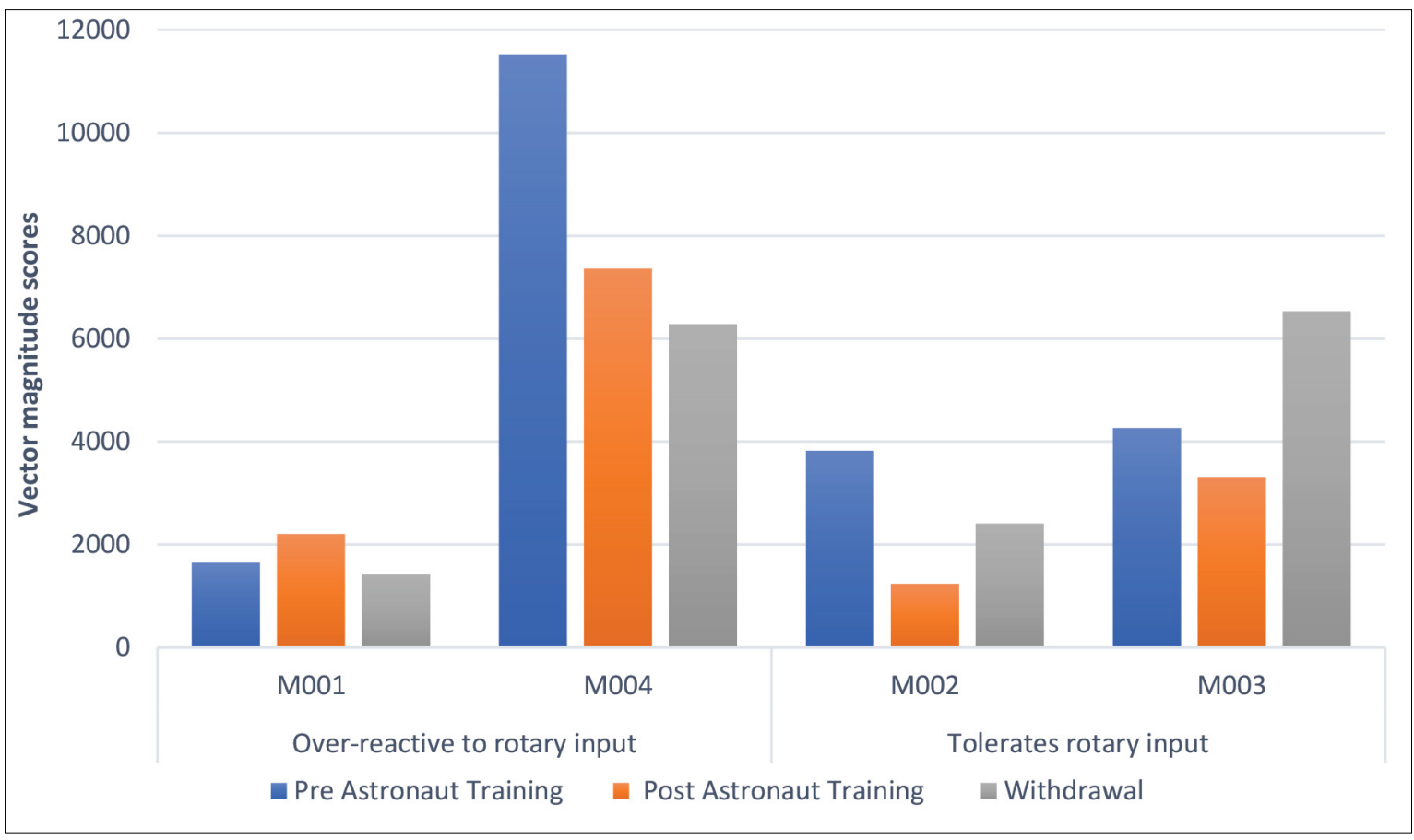

Figure 3:

Accelerometer Vector magnitude inseat movement scores for each participant $(n=4)$. provement was seen in the Withdrawal phase. There was improvement from Pre-Astronaut Training to Post-Astronaut Training for participants who tolerated rotary input and again to Withdrawal.

\section{Postural control}

Changes in postural control were analysed Post-Astronaut Training and after Withdrawal by assessing in-seat posture and in-seat movement:

\section{In-seat posture}

Scores closer to zero indicate better posture; all participants improved between the Pre-Astronaut Training and Post-Astronaut Training except participants $\mathrm{MOOI}$ who remained the same. The posture of participants who could tolerate rotary input at the start of the study deteriorated during the Withdrawal phase, while the posture of participants who were over-reactive to rotary input continued to improve into the Withdrawal phase. (Figure 2 pg 69).

There was improvement indicated by a positive change in scores for posture between Pre-Astronaut Training and Post-Astronaut Training for participants who were both over-reactive to rotary input and who could tolerate rotary input.

At withdrawal there was a very small improvement in participants who were over-reactive to rotary input while the participants who could tolerate rotary input, did not continue to show improvements and their in-seat posture deteriorated. (Table III page 69).

\section{In-seat movement}

The scores from the Actigraph Accelerometer vector magnitude were used to analyse overall fidgety movements (Figure 3 above). A lower score indicates less in-seat movement, and this was found for all participants at Post-Astronaut Training, except for participant M00I who presented with very little movement at Pre-Astronaut Training.

The participants over-reactive to rotary movement, showed similar or less in-seat movement Post-Astronaut Training and at Withdrawal. The remaining participants who tolerated rotary movement, all displayed an increase in in-seat movement at Withdrawal phase with participant $\mathrm{M003}$ increasing to a higher score than that for her Pre-Astronaut Training.
A difference was found for vector magnitude between the PreAstronaut Training and Post-Astronaut Training for participants who were over-reactive and tolerant of rotary input, with a reduction in in-seat movement during the Intervention phase. Participants who were over-reactive to rotary input continued to improve into the Withdrawal phase. A negative difference was found between the Post-Astronaut Training and the Withdrawal phase in participants who tolerated rotary input, indicating that gains made during the Post- Astronaut training were not retained when the intervention was withdrawn. Thus, participants who tolerated rotary input became more fidgety in the Withdrawal phase (Table IV pg7I).

\section{DISCUSSION}

\section{Effects of the Astronaut Training Protocol on vestibular function and postural control}

Findings indicate a change in vestibular function and postural control following the Astronaut Training Protocol for four participants using a case study research design. Clinical change for in-seat posture and in-seat movement was found Post-Astronaut training for all participants. This indicated that both groups displayed improved posture with less fidgeting at the table Post-Astronaut Training. Co-contraction of the trunk is partially based on semi-circular canal inputs transported via the lateral vestibular spinal tract which receives information from both the otolith organs and semi-circular canals ${ }^{7}$. These then innervate the muscles in the spinal cord of the cervical, lumbar and sacral areas ${ }^{5}$ which then facilitate postural control of upright posture against gravity.

\section{Participants: over-reactive to rotary input}

Participants $\mathrm{MOOI}$ and $\mathrm{M004}$ displayed autonomic nervous system responses indicative of over-reactivity to rotary input, thus fewer revolutions were done in each Astronaut Training session. However, these participants attended the eight Astronaut Training sessions over a shorter period and both showed improvements in in-seat posture and in-seat movement Post-Astronaut Training. These improvements continued into the Withdrawal phase. The increased frequency of the Astronaut Training Protocol may have had a positive impact on their results. Vestibular input can accumulate and last in the body for a few hours after receiving stimulation ${ }^{36}$. 
Table IV: Combined Accelerometer Vector magnitude in-seat movement scores Pre-Astronaut Training, Post-Astronaut Training and Withdrawal phases

\begin{tabular}{|c|c|c|c|}
\hline $\begin{array}{l}\text { In-seat } \\
\text { movement }\end{array}$ & $\begin{array}{l}\text { Median (Lower } \\
\text { Quartile and } \\
\text { Upper Quartile) }\end{array}$ & \multicolumn{2}{|c|}{$\begin{array}{l}\text { Difference in Median } \\
\text { Scores }\end{array}$} \\
\hline \multicolumn{4}{|c|}{ Over reactive to rotary input $(n=2)$} \\
\hline $\begin{array}{l}\text { Pre-Astronaut } \\
\text { Training }\end{array}$ & $\begin{array}{l}6582.77(1652.18- \\
11513.37)\end{array}$ & \multirow{2}{*}{$\begin{array}{l}\text { Pre-Astronaut } \\
\text { Training to } \\
\text { Post-Astro- } \\
\text { naut Training }\end{array}$} & \multirow{2}{*}{1793.83} \\
\hline $\begin{array}{l}\text { Post- Astro- } \\
\text { naut Training }\end{array}$ & $\begin{array}{l}4788.94(2212.02- \\
7365.87)\end{array}$ & & \\
\hline Withdrawal & $\begin{array}{l}3855.79(1423.86- \\
6287.73)\end{array}$ & $\begin{array}{l}\text { Post-Astro- } \\
\text { naut Training } \\
\text { to Withdrawal }\end{array}$ & 933.15 \\
\hline \multicolumn{4}{|c|}{ Tolerates rotary input $(n=3)$} \\
\hline $\begin{array}{l}\text { Pre-Astronaut } \\
\text { Training }\end{array}$ & $\begin{array}{l}4049.46(531.88- \\
4270.45)\end{array}$ & \multirow{2}{*}{$\begin{array}{l}\text { Pre-Astronaut } \\
\text { Training to } \\
\text { Post-Astro- } \\
\text { naut Training } \\
\end{array}$} & \multirow{2}{*}{1770.30} \\
\hline $\begin{array}{l}\text { Post- Astro- } \\
\text { naut Training }\end{array}$ & $\begin{array}{l}2279.16(669.14- \\
3316.16)\end{array}$ & & \\
\hline Withdrawal & $\begin{array}{l}4474.27(2414.16- \\
6534.38)\end{array}$ & $\begin{array}{l}\text { Post-Astro- } \\
\text { naut Training } \\
\text { to Withdrawal }\end{array}$ & -2195.11 \\
\hline
\end{tabular}

Continuous vestibular input of the correct duration and intensity may result in better integration of the vestibular system and may explain the changes observed for participants $\mathrm{M00I}$ and M004. This could indicate that children with an over-reactivity to rotary input may benefit from increased number of sessions of the Astronaut Training Protocol.

Balance scores that deteriorated in the Post-Astronaut Training phase however improved at Withdrawal. Participant M00I's balance scores Post-Astronaut Training showed a large deterioration which could have skewed the overall scores. This could have been due to decreased motivation to participate in the balance test on that particular day ${ }^{37}$. Participant M004's balance improved PostAstronaut Training but remained below average. This may be due to the balance difficulties being postural-based rather than only vestibular, such as that of poor postural alignment, stability of the feet and ankles and hip co-contraction ${ }^{38}$.

\section{Participants: tolerant of rotary input}

Participant M002 displayed concentration difficulties and was diagnosed with ADHD and placed on Ritalin after the study was completed. Participant $\mathrm{M003}$ was diagnosed with ADHD and placed on Concerta during the Withdrawal phase. Both these participants were able to tolerate rotary vestibular input. Studies have shown that children with ADHD have subtle abnormalities in the central nervous system ${ }^{39}$, sensory processing difficulties ${ }^{40}$ and almost half of children with ADHD have vestibular deficits which impact the semi-circular canals and otolith organs. Clark et al. ${ }^{41}$ found vestibular stimulation in children with ADHD was effective in reducing the effects of ADHD when done three times per week for 12 weeks. While these studies also showed some maintenance of gains in reduced impulsivity on follow up, they did not measure vestibular function or postural control.

Both participants tolerant of rotary input showed an improvement Post-Astronaut Training in terms of in seat posture and in-seat movement, however there was a deterioration into the Withdrawal phase. This indicated that without the intense vestibular input received in the Astronaut Training Protocol, a regression in in-seat behaviour was observed. This confirms the literature which states the vestibular system is needed for an upright posture against gravity and thus postural control ${ }^{8-10}$ which was achieved by stimulating the different vestibular receptors in the Assonant Training. Consistency of therapy impacted the results. Participant $\mathrm{M003}$ was inconsistent during the Withdrawal phase and it impacted all of her scores which were worse than her Pre-Astronaut Training Baseline.

Participants who can tolerate rotary input, as well as having a diagnosis of ADHD, associated with concertation deficits, appear to need more vestibular input to activate their postural control to assist in their in-seat behaviour. These participants may have benefited from more Astronaut Training sessions since continued vestibular stimulation may be beneficial in children with $\mathrm{ADHD}^{42}$. Clark et al. ${ }^{41}$ recommended vestibular input three times per week for 12 weeks and according to Toyoma ${ }^{25}$, this programme is used in conjunction with sensory-based occupational therapy for up to three months.

Participant M002 showed improvements Post-Astronaut Training in balance with participant $\mathrm{M003}$ having no change which reinforces the literature stating that stimulation of the otolith organs has an impact on balance ${ }^{36}$. An overall improvement in balance was seen during the Astronaut Training Protocol and further improvement was seen through stimulating the otolith organs in sensory based occupational therapy by working on the vestibular system using a variety of swings, balancing activities, and inverting the body during games. Other factors that could affected balance were righting and equilibrium reactions ${ }^{43}$, biomechanical difficulties in body alignment, ankle stability and anticipatory postural adjustments ${ }^{44}$ and proprioception ${ }^{38}$. Some of these areas were observed and addressed but not specifically targeted during the Astronaut Training. These areas were, however, often addressed in sensory-based occupational therapy, which could explain why further improvement was seen at Withdrawal for participant M002.

\section{LIMITATIONS}

A limitation of this study was the variations in consistency and intensity of the therapy. Some participants received therapy more than once per week while others only once a week. Participant M003 did not attend therapy consistently due to parent schedules and school holidays and the greater inconsistency was during the Withdrawal phase, and this appeared to have impacted on the results as her scores deteriorated being worse than at baseline. There were limitations with the assessments used. Assessing balance with the eyes closed may have been a more sensitive way to assess vestibular processing due to the elimination of visual input. The in-seat posture assessment was adapted from the Chailey Levels of Postural Ability $^{3 !}$ for the purpose of this study, and norms were measured against the same criteria for each participant. However, this was not a standardised test and therefore there were no $\mathrm{z}$ scores for the in-seat posture assessment. There is also no literature that indicates what the normal number of in-seat movements during table-top activities is for children. As a result, in-seat movement raw scores were compared against their own movement scores to determine change.

\section{CONCLUSION}

This research investigated the effect of the Astronaut Training Protocol in treating the vestibular system that influences balance and postural control and whether vestibular input would impact in-seat posture and in-seat movement. Three of the four participants showed improvement in their balance, in-seat posture and in-seat movement when comparing their Pre-Astronaut results to 
their Withdrawal phase results. Each participant presented with different findings due to their unique difficulties.

It is important to determine if a child is over-reactive to rotary input at the start of the treatment and how many rotations they can tolerate. Participants with over-reactivity to rotary input, who attended Astronaut Training sessions with increased frequency, appeared to show greater changes in in-seat behaviour Post-Astronaut Training with continued smaller improvements into Withdrawal. Whereas participants who could tolerate rotary input showed improved in-seat behaviour Post-Astronaut Training with a deterioration into Withdrawal showing the need for more vestibular input to activate their postural control, which facilitated better upright posture with less fidgeting. These participants would most likely benefit from more than eight sessions of Astronaut Training to have greater carry-over into Withdrawal of the protocol.

The Astronaut Training Protocol can be considered to have a positive impact on a child's in-seat posture and in-seat movement as seen by the large clinical effect on these two areas Post-Astronaut Training. This treatment approach could therefore be used as a modality, in conjunction with sensory-based occupational therapy, to improve in-seat behaviour in the classroom. More research into the intensity and frequency of the programme should be considered.

\section{Acknowledgement}

The study was funded by an Endowment Grant from the Faculty of Health Science at the University of the Witwatersrand.

\section{AUTHOR CONTRIBUTIONS}

Gabrielle Katzenellenbogen conceptualised and conducted the study. Denise Franzsen and Janine van der Linde supervised the study. All three authors conceptualised and contributed to writing the article.

\section{REFERENCES}

I. Bundy A. Sensory Integration Theory and Practice. Philidelphia: FA Davis; 2002.

2. De Jager M. Mind Moves: Moves that mend the mind. Johannesburg: Mind Moves Institute; 2009.

3. Hanscom A. Balanced and barefoot: How unrestricted outdoor play makes for strong, confident and capable children. Oakland: New Harbinger; 2016.

4. Pfeiffer B, Henry A, Miller S, Witherell S. Effectiveness of disc "O" sit cushions on attention to task in second-grade students with attention difficulties. American Journal of Occupational Therapy. 2008;62(3):274-28I. doi:http://doi.org/10.5014/ajot.62.3.274

5. Shumway-Cook A, Woollacott MH. Chapter I0: Abnormal Postural Control. In: Lupash E, editor. Motor Control Translating Reasearch into Clinical Practice fourth edition. Baltimore: Lippincott Williams \& Wilkins; 2012. p. 264-265.

6. Nichols DS. Development of postural control. In: Motor Control: Translating Research into Clinical Practice: Fourth Edition. Missouri: Elsevier Mosby; 2014. p. 195-213. doi:http://doi.org/I0.5040/978|492595 I5 I.ch-005

7. Shumway-Cook A, Woollacott MH. Chapter 7: Normal postural control. In: Lupash E, editor. Motor Cotrol: Translating Research into Clinical Practice, fourth edition. Baltimore: Lippincott Williams \&Wilkins; 2012. p. 16I-194.

8. Hardy L, Dyer J. Revising the vestibular system. SensorNet; 2013.

9. Lane S. Structure and Function of the Sensory Systems. In: Bundy A, Lane S, editors. Sensory Integration: Theory and Practice. 2nd ed. Philadelphia: F A Davis Company; 2002. p. 35-70.
10. Mailloux Z, Leao M, Becerra TA, Mori AB, Soechting E, Smith Roley $S$, Buss N, Cermak SA. Modification of the postrotary nystagmus test for evaluating young children. American Journal of Occupational Therapy. 2014;68(5):514-521. doi:http://doi.org/I0.5014/ajot.2014.011031

II. de Quiros J, Schrager O. Neuropsychological Fundamentals in Learning Disabilities. California: Academic Therapy Publications; 198I. doi:http://doi.org// 0.50 I4/ajot.35.5.340a

12. Mulligan S. Validity of the Postrotary Nystagmus Test for Measuring Vestibular Function. OTJR: Occupation, Participation and Health. 20I I;3I (2):97-104. doi:http://doi.org/10.3928/15394492-20100823-02

13. Clements R. An Investigation of the Status of Outdoor Play. Contemporary Issues in Early Childhood. 2004;5(I):68-80. doi:http://doi.org//0.2304/ciec.2004.5.1.10

14. Bassok D, Latham S, Rorem A. Is Kindergarten the New First Grade? AERA Open. 2016;2(I):233285841561635. doi:http://doi.org/10.1 177/2332858415616358

15. Amundson SJ. Chapter 17: Prewriting and handwriting skills. In: Falk K, editor. Occupational Therapy for Children . Missouri: Elsevier Mosby; 2005. p. 587-6I4.

16. Blanche E, Botticelli T, Hallaway M. Neuro-developmental Treatment and Sensory Integration Principles an approach to pediatric therapy. Arizona: Therapy Skill Builder; 1995.

17. Wang TN, Howe TH, Hinojosa J, Weinberg SL. Relationship between postural control and fine motor skills in preterm infants at 6 and 12 months adjusted age. American Journal of Occupational Therapy. 20I I;65(6):695-70 I. doi:http://doi.org/10.50।4/ajot.20II.00I503

18. Ayres A. Sensory Integration and Praxis Tests Manual. Torrance: Western Psychological Services; 2012.

19. Henderson S, Sugden D, Barnett A. Movement assessment battery for children- (Movement ABC-2). 2nd ed. London: The Psychological Corporation; 2007.

20. Igarashi G, Karashima C, Hoshiyama M. Effect of Cognitive Load on Seating Posture in Children. Occupational Therapy Intenational. 2016;23(I):48-56. doi:http://doi.org/I0.1002/oti. 1405

2I. Vuillerme N, Nougier V. Attentional demand for regulating postural sway: The effect of expertise in gymnastics. Brain Research Bulletin. 2004;63(2): $161-165$. doi:http://doi.org/10.1016/j.brainresbull.2004.02.006

22. Domljan D, Vlaović Z, Grbac I. Pupils' working postures in primary school classrooms. Periodicum Biologorum. 2010; I I 2(I):39-45.

23. Bennie $C$. Investigation into the impact of cognitive load in children with and without identified postural control. University of the Witwatersrand; $201 \mathrm{I}$.

24. Kawar M, Frick S, Frick R. Astronaut Training: A Sound Activated Vestibular- Visual Protocol. Madison: Vital Links; 2005.

25. Toyama Z. Determining Sensory-Based Interventions Used by Occupational Therapists. 2013.

https://soundideas.pugetsound.edu/ms_occ_therapy/85

26. Yin R. Case Study Research and Applications: Design and Methods. Los Angeles: Sage Publications; 2017.

27. Ayres A. Clinical Observations Adapted from J Ayres Administration and Interpretation. Revised. Johannesburg: South African Institute of Sensory Integration Research Committee; 2005.

28. Ayres A. Interpreting the Southern California Sensory Integration Test. Los Angeles: Western Psychological Services; 1976.

29. Ayres A. Southern California postrotary nystagmus test: manual. Los Angeles: University of Southern California; 1975.

30. Kimball JG. Normative comparison of the Southern California postrotary nystagmus test: Los Angeles vs. Syracuse data. American 
Journal of Occupational Therapy. 198I;35(I):21-25.

doi:http://doi.org/10.5014/ajot.35.1.21

31. Rosenbloom L. The Chailey approach to postural management. East Sussex: Active Design; 2020.

doi:http://doi.org/I0.1 136/adc.85.2.175

32. Rapport MD, Bolden J, Kofler MJ, Sarver DE, Raiker JS, Alderson RM. Hyperactivity in boys with attention-deficit/hyperactivity disorder (ADHD): A ubiquitous core symptom or manifestation of working memory deficits? Journal of Abnormal Child Psychology. 2009;37(4):52I-534.

doi:http://doi.org/10.1007/s 10802-008-9287-8

33. Actigraph. User Guide: Actigraph wGT3X-BT+ Actilife. 2016 [accessed 2018 Dec I]. http://actigraphcorp.com/wp-content/uploads/2017/02/ActiGraph_wGT3X-BT_UserGuide_12312016_FINAL_WEB.pdf

34. Tryon W. Activity measurement in psychology and medicine. New York: Springer Science \& Business Media; 2013.

35. Busk P, Serlin R. Meta-analysis for single-case reasearch. In: Erlbaum L, editor. Single-case research design and analysis: New directions for psycology and education. New Jersey: Hillsdale; 1992. p. |87-2| 2.

36. Lane S. Chapter 4: Sensory Modulation. In: Bundy A, Lane S, editors. Sensory Integration: Theory and Practice 2nd edition. Philadelphia: F A Davis Company; 2002. p. I0I-I 22.

37. Sideridis GD, Scanlon D. Motivational Issues in Learning Disabilities. Learning Disability Quarterly. 2006;29(3): 131-135. doi:http://doi.org// 0.2307/30035503

38. Magrun W. Neural Systems Integration: Improving performance in Children with Learning Disabilities. Clinician's View; 2016.

https://www.clinicians-view.com/BookPreviews/LD5Preview.pdf ed. Buffalo: Clinician's view.

39. Castellanos XF, Lee PP, Sharp W, Jeffries NO, Greenstein DK, Clasen LS, Blumenthal JD, James RS, Ebens CL, Walter JM, et al. Developmental trajectories of brain volume abnormalities in children and adolescents with attention-deficit/hyperactivity disorder. Journal of the American Medical Association. 2002;288(I4): 1740-1748. doi:http://doi.org/10.100I/jama.288.14.1740

40. Panagiotid M, Overton PG, Stafford T, Panagiotidi M, Overton PG, Stafford T. The relationship between ADHD traits and sensory sensitivity in the general population. Comprehensive Psychiatry. 2018;80: 179-185.

doi:http://doi.org/10.1016/j.comppsych.2017.10.008

4I. Clark L, Arnold LE, Crowl L, Bozzolo H, Peruggia M, Ramadan Y, Bornstein R, Hollway JA, Thompson S, Malone K, et al. Vestibular stimulation for ADHD: Randomized controlled trial of comprehensive motion apparatus. Journal of Attention Disorders. 2008; I I (5):599_ 6I I. doi:http://doi.org/ I0. I I77// 0870547073 I 1042

42. Arnold LE, Clark DL, Sachs LA, Jakim S, Smithies C. Vestibular and visual rotational stimulation as treatment for attention deficit and hyperactivity. The American Journal Of Occupational Therapy. 1985;39(2):84-91. doi:http://doi.org/10.50|4/ajot.39.2.84

43. Bundy AC. Chapter 7: Assessing Sensory Integrative Dysfunction. In: Bundy A, Lane S, editors. Sensory Integration: Theory and Practice 2nd edition. Philadelphia: FA Davis; 2002. p. 169-198.

44. Horak FB, Wrisley DM, Frank J. The Balance Evaluation Systems Test (BESTest) to Differentiate Balance Deficits. Physical Therapy. 2009;89(5):484-498. doi:http://doi.org//0.2522/ptj.2008007। 